\title{
The EVOLUTION OF PUBLIC SPENDING ON HIGHER EDUCATION IN A DEMOCRACY
}

\author{
ALEXANDER HAUPT \\ CESIFO WORKING PAPER NO. 1631 \\ CATegory 2: Public ChOICE \\ DECEMBER 2005
}

An electronic version of the paper may be downloaded

- from the SSRN website:

wWw.SSRN.com

- from the CESifo website:

www.CESifo-group.de 


\title{
The EVOlution OF PUBLIC SPENDING ON HIGHER EDUCATION IN A DEMOCRACY
}

\begin{abstract}
This paper analyses political forces that cause an initial expansion of public spending on higher education and an ensuing decline in subsidies. Growing public expenditures increase the future size of the higher income class and thus boost future demand for education. This demand shift implies that the initial subsidy per student becomes too expensive to be politically sustainable. Despite a voters' backlash that curbs education subsidies, overall enrolments continue to rise. But the participation rate of the children of lower income families, that went up in the expansion period, declines over time, both in absolute terms and relative to the rate of their counterparts from higher income households.
\end{abstract}

JEL Code: I22, I28, D72, H52, O15.

Keywords: higher education, voting, social stratification, social mobility, overlapping generations.

\author{
Alexander Haupt \\ Department of Economics \\ European University Viadrina \\ P.O. Box 1786 \\ 15207 Frankfurt (Oder) \\ Germany \\ haupt@euv-frankfurt-o.de
}

November 2005. I am grateful to T. Blumkin, J. Fischer, M. Gradstein, K.A. Konrad, W. Peters and H. Seitz for valuable comments, and thank participants at the Conferences of the European Public Choice Society in Durham and the Royal Economic Society in Nottingham, the CESifo-NHH Norwegian-German Seminar on Public Economics in GarmischPartenkirchen, a workshop on public economics in Berlin, and seminars at the University of Mannheim and the European University Viadrina for helpful discussions. An initial draft was written while I was visiting the Economics Department of the University of Colorado at Boulder. I have benefited from inspiring discussions particularly with C.A.M. de Bartolome, M.F. Iyigun and E. Janeba and thank the members of the department for their hospitality. I am grateful to the Fritz Thyssen Stiftung for funding this research visit. 


\section{Motivation}

Many European countries traditionally have generous public systems of higher education. Tuition at universities is usually free, and a combination of grants and (interest free) loans provides a fairly attractive economic environment for students even from lower income families. But the mood seems to be changing in many of these 'traditional' European countries, and the call for students to contribute more to the costs of their education has become louder. In England, universities can now charge up to $£ 3,000$ in tuition fees instead of the former flat rate of $£ 1,115$. Despite substantial opposition and the emphasis of the current British government on education, Tony Blair pushed through this new legislation, which he considered to be "a very major flagship reform" from which "there will be absolutely no retreat" (see Economist, 2003). On the other side of the channel, so called long term students are already being asked for money in some parts of Germany, and there is a growing debate about the introduction of general tuition fees. The government of North Rhine-Westphalia, Germany's most populous state, intends to introduce general tuition fees by 2007. Even social democratic governments, which have traditionally carried the banner of free education, are rethinking their general approach to education policy. All in all, public opinion has shifted in favour of requiring the recipients of higher education to pay more.

There are various possible explanations for this emerging shift in attitude. One fashionable line of reasoning links the recent development to globalisation. It stresses that governments might be forced to partly withdraw from the education system because intensified international tax competition restricts their ability to raise the necessary revenues. Moreover, increasing mobility of skilled workers means that the social returns to education do often not accrue in the country that has financed the accumulation of human capital, thus reducing the incentives to subsidize education. ${ }^{1}$

In contrast to this argumentation, I provide an explanation for the evolving shift in education finance that does not refer to economic integration and its implications. Instead, the attention is directed to the changes in political preferences and political power over time that were caused by the initial expansion of public education itself.

The basic argument runs as follows: Skilled parents are the main driving force behind subsidizing higher education, since most of the college and university students are their children. But, at least at an early stage, their numbers are too small to be pivotal. Only when the size of the educated class exceeds a threshold value, does a 'coalition' in favour of government intervention, consisting of a majority of

\footnotetext{
${ }^{1}$ There are a number of papers which explore the relationship between labour market integration and public spending on education from different angles. See, for instance, Andersson and Konrad (2003), Haupt and Janeba (2004), Poutvaara (2001), or Wildasin (2000).
} 
the skilled citizens and of lower income households with very gifted children, push through extensive public education spending. Higher subsidies foster the number of students and increase the number of the skilled people in the future. This educational 'take-off', however, later provokes a backlash. Since a bigger educated class boosts the demand for higher education, public commitments become more expensive. Even the supporters of government intervention then favour smaller subsidies and call for larger private contributions. After an expansion phase, public spending on higher education declines. Despite the cut in subsidies, the number of students increases further, but this continuing rise in enrolment is the result of changes in class size and the ensuing shift in demand for higher education.

The social implications are ambiguous. Resources are redistributed from those families whose children receive only a basic education to those whose children attend universities. This redistribution is mainly in favour of households with skilled parents. But, although only a minority of the children from unskilled parents benefits from the subsidies, these transfers foster equality of opportunity and intergenerational income mobility. Conversely, the decline in public spending reduces the participation rate of children from lower income families in higher education, both in absolute terms and relative to that of children from higher income households. It thus sets the social structure in concrete.

This line of reasoning is analysed in a model with two overlapping generations in which young people with different ability attend universities or receive only basic schooling. The education choice takes place in each period's second stage, after the electorate has voted on public education spending. The present student body forms the higher income class in the next period. Thus, two succeeding periods are linked, since today's choices shape tomorrow's social stratification, which in turn affects future decisions.

The explicit dynamic modelling distinguishes the current paper from the strand of literature that deals with democratic choices for financing higher education in a static framework. Fernandez and Rogerson (1995) show that redistribution from lower income to better off families occurs in a political equilibrium. The majority favours only partial subsidisation of education as a device to exclude poorer citizens from attending colleges and taking advantage of the transfers. ${ }^{2}$ In contrast to Fernandez and Rogerson (1995), households differ in income and ability of their children in the present paper. As in De Fraja (2001), the battle lines are, thus, within income groups and not only between different classes. De Fraja (2001) contrasts an admission test and a subsidy in a framework in which future earnings are uncertain

\footnotetext{
${ }^{2}$ Some more 'optimistic' explanations for government intervention in the political equilibrium are mentioned in section 5 .
} 
and people are risk averse. The two measures increase equality of opportunity, but affect equity ambiguously. A subsidy, for instance, makes, in particular, lower income households whose children do not attend universities worse off. This issue is taken up in the present paper too. But unlike both Fernandez and Rogerson (1995) and De Fraja (2001), the current analysis explicitly focuses on how education policy evolves over time, reflecting shifts in political preferences and power.

A dynamic political-economic analysis of education and income distribution has been the subject of research in the second strand of literature closely related to the present paper. Cardak (2004), Glomm and Ravikumar (1992), and Gradstein and Justman (1997) compare public and private education in an endogenous growth framework. The applied approaches enable them to gain substantial insights into the relationship between growth, income inequality, and education, but their frameworks are not suitable for exploring the issues of the present paper. In their contributions, the specification of the utility function and the learning technology, combined with a proportional tax on income, implies that all individuals at all times prefer the same tax rate in the public education regime. So any conflict of interests is excluded from the outset. By contrast, in the current paper, citizens differ profoundly in their favoured policies in each period, and political preferences change over time. Voters also disagree on the optimal policy in Saint-Paul and Verdier (1993), where the interplay between democracy, income distribution, and growth is examined. Nevertheless, the political conflicts are again very different from those in the present paper, since in their model all individuals receive publicly funded education in the same way. ${ }^{3}$

To sum up, unlike the static models mentioned above, the current paper explores the evolution of higher education policy. In contrast to the dynamic approaches referred to above, it does this in a framework where citizens differ in their preferred policies and where only a subset of the population benefits from education policy. In this respect, the present contribution extends the two branches of literature mentioned and fills a gap between them.

The remainder of this paper is organized as follows: in the next section, the basic elements of the model are described. Section 3 explores the education choices and the opposing political preferences. The evolution of the education policy, the number of students and the participation rates is analysed in section 4. Afterwards,

\footnotetext{
${ }^{3}$ There are a number of further papers which analyse intergenerational earning mobility but consider education policy as exogenously given (for instance, Bénabou, 2002, Glomm and Ravikumar, 2003, Iyigun, 1999, and Loury, 1981). These contributions can be regarded as complementary to the political economic approaches. Others, like Perotti (1993), examine long run income distribution and human capital investments in the case of endogenously determined redistributive policies (but ignore education policy).
} 
some generalisations and extension are discussed. This enables us to assess the political implication of the present analysis in a broader context. The paper ends with some concluding remarks.

\section{The Model}

This section presents a simple dynamic model for studying the evolution of public education spending and social stratification in a democracy. To this end, let us consider a society with two overlapping generations. In each period, the citizens first democratically choose a tax that finances an education subsidy. Depending on the policy implemented, the decisions on the education of the children are made afterwards. Political preferences and education choices vary between households, since families differ in two dimensions. The 'old' generation is divided into two income groups, and the young people differ in their innate ability to acquire human capital.

More precisely, the economy consists of a continuum of families, each comprising one parent and one child, with total mass equal to one. Every member of the old generation inelastically supplies one unit of labour, whereas the young people attend institutions of higher education, for brevity referred to as universities, or receive only some basic education. For analytical convenience, the following analysis abstracts from the fact that the durations of the two levels of education are different. Instead, the differences are summed up by the single parameter 'costs of education', which vary between the two education levels and, as described below, between individuals.

Households are heterogeneous in two respects. First, they can be divided into two groups according to the income of the adults. Depending on whether the old people attended university or not in the preceding period, they have either a skilled or unskilled occupation and receive a gross wage $w_{H}$ or $w_{L}$, where $w_{H}>w_{L}$ holds. The former group is referred to as the higher income class, and its counterpart is referred to as the lower income class.

Second, children differ in their innate ability to acquire human capital. This feature is again captured by the costs of education. ${ }^{4}$ The lower the talent, the higher are the costs of receiving a university degree. For simplicity, assume that costs of basic schooling equal zero for all individuals while higher education costs are uniformly distributed on the support $[\underline{z}, \bar{z}]$. The density function is identical for

\footnotetext{
${ }^{4}$ Alternatively, different ability levels can, for instance, be modelled by different probabilities of receiving a university degree or by different study durations (and thus distinct individual opportunity costs). These approaches lead to the same qualitative results, but they make the model less tractable without providing additional insights.
} 
all young people of the two classes. It is invariant over time and common knowledge.

The parent-child household is regarded as the basic socioeconomic unit 'ruled' by the parent. The parent determines the spending on (family) consumption and education reflecting her valuation of these two components. ${ }^{5}$ Her preferences are represented by the utility function

$$
U_{i j}=U\left(x_{i j}, \theta_{i j}\right), \quad j=H, L,
$$

where $x_{i j}$ denotes consumption of the $i$ th household of income group $j$ in the current period. The variable $\theta_{i j}$ captures the utility the household attaches to the child's education. If the child goes to university, $\theta_{i j}$ equals $\theta$; otherwise $\theta_{i j}=\underline{\theta}<\theta$ holds. Hence, a parent is altruistic in the sense that she values her descendant's quality of education, which in turn determines the earning capacity she bequeaths to her offspring. ${ }^{6}$

The twice-continuously differentiable utility function is assumed to fulfil three properties: (i) utility is strictly increasing in both consumption and education quality, (ii) $U\left(x_{i j}, \underline{\theta}\right)>U(0, \theta)$ holds for all $x_{i j}>0$, and (iii) if $U\left(x^{\prime}, \underline{\theta}\right)=U\left(x^{\prime \prime}, \theta\right)$, then $U\left(\lambda x^{\prime}, \underline{\theta}\right)=U\left(\lambda x^{\prime \prime}, \theta\right)$ for any $\lambda>0$. The first property is obvious. Property (ii) excludes implausible boundary solutions without any consumption. As explored below, the third property means that the willingness to pay for higher education is proportional to net income. This property is fulfilled, for instance, by the Cobb-Douglas function $U\left(x_{i j}, \theta_{i j}\right)=x_{i j}^{\alpha} \theta_{i j}^{\beta}, \alpha, \beta>0$, or the quasilinear function $U\left(x_{i j}, \theta_{i j}\right)=\ln x_{i j}+\theta_{i j}$. Since property (iii) is loosely related to the concept of homotheticity, it is referred to as 'quasi'-homotheticity.

A household whose child attends a university receives a uniform subsidy $s, s \geq$

\footnotetext{
${ }^{5}$ The simplification that the parent decides on behalf of her child is widespread in the literature (see, for instance, De Fraja, 2001, and Beviá and Iturbe-Ormaetxe, 2002). This assumption reflects the strong personal and financial ties between parents and their offspring. Parents make, for instance, predetermining schooling decisions at a stage at which the children are more or less passive players without any precise ideas about the implications of these choices for their future. Moreover, young adults face severe credit constraints largely due to information problems and the inability to collateralise human capital. Thus, they can only finance their education if they are supported by their parents or the public. Putting these arguments together, the 'parentocracy' serves as a reasonable proxy of educational decisions. Interestingly, many education subsidies are indeed directly targeted at the parents and not at the students themselves. In many countries, parents are eligible to tax deduction or child related transfers as long as their children attend universities.

${ }^{6}$ Conditioning a parent's choice on the child's education quality or similar 'myopic' variables instead of the child's utility is common in dynamic political-economic analyses. Otherwise, the models are intractable. Cf. Gradstein and Justman (1997) who use the earning capacity of the children as an argument in the parents' utility function. In Glomm and Ravikumar (1992), for instance, parents benefit from the quality of schools.
} 
0. This subsidy is financed by a lump-sum tax $t$ on the working generation. A household's budget constraint is thus given by

$$
\begin{aligned}
x_{i j} & =w_{j}-t \quad \text { (in the case of basic education) } \\
\text { and } \quad x_{i j} & =w_{j}-t+s-z_{i j} \quad \text { (in the case of higher education), }
\end{aligned}
$$

where $z_{i j}$ denotes the child's higher education costs.

The tax is non-negative and, to avoid the unrealistic case of de facto expropriation, is assumed to be limited to $\bar{t}<w_{L}$. Additionally, the education policy is constrained by the requirement of a balanced government budget in each period:

$$
B=t-s E=0
$$

where $E$ denotes the 'number' or, more precisely, the mass of university students. ${ }^{7}$ Tax revenues $t$ (recall that the size of each generation is normalized to one) have to cover public education spending $s E$.

Given the households' and government's budget constraints, the utility-maximising parents make two decisions. In the first stage, they democratically adopt a tax $t$ that finances the uniform education subsidy $s$. A proposal $t$ is collectively chosen if it wins every pairwise comparison against all other candidates. The assumption that only the parents constitute the electorate captures the fact that when students enter university they have barely voted once. The education system can thus be considered as exogenous for the young adults, and depends on the choice of the parents.

In the second stage, the parents decide whether they will provide the financial means for a higher education of their children, taking full account of the tax and its implications on the subsidy level. The households' consumption then results simply as the difference between net income on the one hand and education expenditures net of subsidy on the other hand.

Note that the current approach is compatible with different institutional settings in the education sector. In the case of private universities, the households are often the immediate recipients of the transfers, using the subsidies to pay the tuition fees and to cover the living costs of the students. If universities are publicly run, a large part of the subsidy might go directly to these institutions and only a small share is transferred to the households. For a family, however, it makes no difference whether subsidies are directly paid to universities or whether the households receive assistance to cover the university cheque.

\footnotetext{
7The term 'number' is often used, although it is not the very exact technical expression in the case of a continuum of households.
} 
As will soon become evident, applying lump-sum taxes enables me to focus on the conflict of interests between families whose children attend university on the one side and those whose children do not on the other side. The changing constellation in this conflict over time is already sufficient to explain a take-off in public spending and the ensuing decline in education expenses.

\section{Education Choice and Political Preferences}

The ultimate goal is to explain the political evolution of public education spending in a democracy and the social stratification implied. Before we turn to the dynamics of the system, the 'static' equilibrium in a single period has to be analysed. To this end, the households' education choices for a given policy $(s, t)$ and the relationship between the tax $t$ and the subsidy $s$ are explored first. Based on the insights gained from this exercise, the political preferences and the emergence of two opposing stances can be outlined.

\subsection{Enrolments and Government Budget}

When a household decides on the child's education level, the family's trade-off is straightforward. A young individual goes to university if the household's utility gain resulting from a highly educated offspring outweighs the utility loss induced by the private education spending. The inequality $U\left(w_{j}-t+s-z_{j i}, \theta\right) \geq U\left(w_{j}-t, \underline{\theta}\right)$, which follows from inserting the budget constraint (2) into the utility function (1), provides the necessary and sufficient condition for this to be the case. This condition can be characterised more precisely. In Appendix A, lemma 1 shows that each parent is ready to give up a constant fraction $m \in(0,1)$ of the potential family consumption to finance the education of her child. This conclusion directly follows from the 'quasi'-homotheticity of the utility function (see property (iii) of this function). It, in turn, means that a child attends university if, and only if,

$$
z_{j i} \leq m\left(w_{j}-t\right)+s=: \widehat{z}_{j}(s, t)
$$

holds. The interpretation of (4) is easy. For a given policy $(s, t)$, each parent is willing to give up the share $m$ of the potential consumption level $w_{j}-t$. If this willingness to pay for higher education and the subsidy $s$ are together sufficient to cover the costs $z_{i j}$, the offspring is sent to university.

Condition (4) has two obvious implications. First, facing a trade off between the education level and consumption, parents are more inclined to invest in the human capital of 'low cost' (i.e. highly intelligent) children than in that of costly (i.e. less 
able) ones. Second, since the willingness to pay for education increases in income, the higher income family of the marginal student $\widehat{z}_{H}$ spends more on education than its poorer counterpart. Consequently, children with the same abilities, i.e. same costs $z$, might acquire different levels of human capital, although all parents place the same value on higher education. In this sense, there is no equality of opportunity. The fraction of children from lower-income families attending universities falls below that of wealthier children receiving higher education, i.e.

$$
\gamma_{L}(s, t)=\frac{\widehat{z}_{L}-\underline{z}}{\bar{z}-\underline{z}}<\frac{\widehat{z}_{H}-\underline{z}}{\bar{z}-\underline{z}}=\gamma_{H}(s, t)
$$

where $\gamma_{L}$ and $\gamma_{H}$ denote the respective fractions, referred to as participation rates, and $\widehat{z}_{j}$ is defined by (4). Inequality (5) is backed by broad empirical evidence. In Germany, for instance, the participation rates in 1996 ranged from 0.26 for the 18 to 21 years old from the lowest parental income quartile to 0.45 for those from the highest one, despite rather low income inequality and higher education with no tuition fees (BMBF, 1998). ${ }^{8}$

Using (5), the number of university students is given by

$$
E(s, t)=\gamma_{L}(s, t) L+\gamma_{H}(s, t) H=\gamma_{L}(s, t)+\left[\gamma_{H}(s, t)-\gamma_{L}(s, t)\right] H,
$$

where $L$ and $H$ denote the number of lower-income and higher-income families, respectively. (Recall that the size of the population is normalized to unity, and thus $L=1-H$ holds.) Since the participation rate $\gamma_{H}(s, t)$ is greater than $\gamma_{L}(s, t)$, enrolment $E$ increases in the size $H$ for a given policy $(s, t)$, a relationship which will be important in the following analysis.

For a given tax, the number of students determines the subsidy level, as the government budget constraint (3) shows. This subsidy level, in turn, affects the number of students, as enrolment (6) shows. Taking these interactions between these two figures into account, a unique subsidy $s$ results for each tax $t$ such that (i) the government budget is balanced and (ii) each household's education choice is consistent with utility maximisation for the respective bundle $(s, t)$. (Note that since a single parent has no significant influence on the number of students, she regards the subsidy as independent of her education choice.)

The resulting functional relationship between the tax $t$, which is determined in the first stage, and the subsidy $s$ has two straightforward features. These properties

\footnotetext{
${ }^{8}$ Similarly, in Britain the participation ratio of the highest socioeconomic group was 0.79 in 1995 while that of the lowest group was a mere 0.12 (see Robertson and Hillman, 1997). However, these data have to be interpreted with caution, since the concept of socioeconomic groups encompasses parental occupational status and educational attainment as characteristics and thus differs from a pure income concept.
} 
are formally proven in Appendix A, so that only the basic argument is provided here. First, subsidy $s$ increases in tax $t$, i.e. $d s / d t>0$. A higher tax yields larger revenues. Ceteris paribus, it curbs the households' net incomes and thus the demand for university education. Both larger revenues and lower demand work in favour of a higher subsidy per student.

Second, the marginal effect of a rise in the tax level on the subsidy is the smaller, the higher the tax, i.e. $d^{2} s / d t^{2}<0 .{ }^{9}$ If the tax and, thus, the subsidy and the number of students are rather low, additional revenues stemming from a higher tax are only divided among a small group. The resulting subsidy increase is quite substantial. But the larger the transfer level, the more people attend universities and the larger is the group of recipients demanding their share of additional revenues. The marginal rise in the subsidy then becomes smaller if the tax goes up.

Finally, note that the participation rates are only given by (5) if $\widehat{z}_{j} \in[\underline{z}, \bar{z}]$ holds. To avoid tedious discussions of rather unrealistic corner solutions, the focus is on the cases in which the threshold value $\widehat{z}_{j}(s, t)$ is indeed between $\underline{z}$ and $\bar{z}$. This outcome can be guaranteed by restricting the parameter space:

\section{Assumption 1:}

(a) $\underline{z}<m w_{L}$ and (b) $\bar{z}>m\left(w_{H}-t\right)+s$ for $\{(s, t) \mid t-s E(s, t)=0\}$.

These conditions are easy to interpret. On the one hand, the brightest children of each income group attend university even if there is no government intervention (cf. inequality (4)). On the other hand, no financially feasible bundle $(s, t)$ makes a higher education degree achievable for the least able child in his social class. (Since the restriction $t \in[0, \bar{t}]$ limits the feasible subsidy $s$, there exists a non-empty set of parameters that fulfil this assumption. As will become evident below, a policy such that all people of a generation go to universities would anyhow never achieve a majority even if it were possible. But $\gamma_{H}=1$ could, in principle, result if the cost level $\bar{z}$ was too small. Considering such corner solutions, however, would not generate fruitful insights.)

\footnotetext{
${ }^{9}$ The strictly concave relationship between $s$ and $t$ is guaranteed because (1) innate abilities are uniformly distributed and (2) the willingness to pay for higher education, i.e. $m\left(w_{j}-t\right)$, is proportional to net income. These two characteristics together are sufficient to avoid severe 'technical' complications, particularly with respect to the dynamic analysis. They are, however, not necessary to obtain the following results. These assumptions imply, for instance, that the number of students (6) is linear in the variables $s, t$, and $H$. Thus, secondary effects associated with second derivatives and cross derivatives are neglected. To put it differently, the basic premise is that the 'first-order' effects drive the overall outcome.
} 


\subsection{To be or not to be in Favour of a Subsidy}

Having discussed the relationship between the tax $t$ and the subsidy $s$, we can now turn to the individuals' political preferences. This analysis is rather straightforward in the current framework, since households can be clearly divided into two opposing groups: On the one side, there are all those voters who reject any tax and education subsidy. On the other side, there are the supporters of government intervention. Within the latter group, no conflicts of interests arise, since all parents in favour of public education spending agree on their preferred tax level. Hence, a clear-cut dichotomy between the citizens for and those against public education spending emerges. Let us explore the reasons for this outcome before it is precisely stated in proposition 1 at the end of this section.

Consider first a family whose child receives higher education. Given that the child attends a university, the best policy for the family is the tax $t$ that maximises its utility $U\left(w_{j}-t+s(t)-z_{j i}, \theta\right)$ and thus the differential $s(t)-t$, referred to as net subsidy. Since the government budget constraint yields a strictly concave functional relationship between the variables $s$ and $t$, i.e. $d^{2} s / d t^{2}<0$ (see discussion above and Appendix A), there exists a unique solution $t^{o}$ to this maximisation problem, implying a unique subsidy $s^{o}$.

Formally, this best policy follows from

$$
\max _{s, t} s(t)-t
$$

which yields the first-order condition

$$
\frac{d s(t)}{d t}=1
$$

This condition simply says that, in the optimum, a marginal tax increase equals the induced rise of the subsidy (given a balanced government budget). ${ }^{10}$ Since taxes are lump sum, (8) is identical for the two income groups. Thus, the solution $t^{o}$ does not depend on whether a higher income or a lower income household is considered. It is also not affected by the $z_{j i}$-type. To sum up, given that a child attends a university the tax $t^{o}$ and the corresponding subsidy $s^{o}$ are the best that can happen from the perspective of her parent.

By contrast, if a household's child does not receive higher education, the parent obviously opposes any tax, since the resulting transfers only benefit other families. In this case, the best policy is $t=0(=s)$. The remaining question is whether a parent prefers the tax $t^{o}$ and sending her child to a university to the policy $t=0$. Evidently, the former alternative is the family's best choice if, and only

\footnotetext{
${ }^{10}$ As $d s /\left.d t\right|_{t=0}>1$ holds, both optimal tax and subsidy have to be strictly positive.
} 
if, $U\left(w_{j}-t^{o}+s^{o}\left(t^{o}\right)-z_{j i}, \theta\right) \geq U\left(w_{j}, \underline{\theta}\right)$ is fulfilled. Since the willingness to give up consumption is proportional to the potential consumption level $w_{j}$ (cf. lemma 1 in Appendix A and the discussion above), a parent votes for the tax $t^{o}$ if, and only if,

$$
z_{j i} \leq m w_{j}-t^{o}+s^{o}\left(t^{o}\right)=: \widetilde{z}_{j}\left(s^{o}\left(t^{o}\right), t^{o}\right)
$$

holds. This condition means that a parent favours the tax $t^{o}$ if the resulting net subsidy $s^{o}-t^{o}$ and her gross willingness to pay for education $m w_{j}$ together are sufficient to cover the costs $z_{j i}$. If this is not the case, the citizen prefers to pay no taxes at all and to relinquish higher education for her child.

Condition (9) has two important implications. First, since the gross willingness to pay increases in the wage, a smaller fraction of the lower income class than of the higher income class advocates a subsidy, i.e.

$$
\eta_{L}\left(s^{o}\left(t^{o}\right), t^{o}\right)=\frac{\widetilde{z}_{L}-\underline{z}}{\bar{z}-\underline{z}}<\frac{\widetilde{z}_{H}-\underline{z}}{\bar{z}-\underline{z}}=\eta_{H}\left(s^{o}\left(t^{o}\right), t^{o}\right)
$$

where $\eta_{L}$ and $\eta_{H}$ denote the respective fractions and $\widetilde{z}_{j}$ is defined by (9). The stronger political support of skilled parents simply stems from the stronger representation of their children at universities.

Second, in each income group the parents whose children receive higher education outnumber the parents who support the proposal $t^{o}$, i.e. $\gamma_{j}>\eta_{j}$ for $t=t^{o}$ and $s=s^{o}$. This implication can be easily explained. If the proposal $t^{o}$ is already implemented, the tax payment has to be made anyway and is sunk. In this case, some families are willing to bear the remaining private education costs $z_{j i}-s^{o}$ and send their children to universities, although they prefer no tax at all at the political stage and just a basic education for their children.

More importantly, the optimal values $t^{o}$ and $s^{o}$ strictly decrease in the number of educated parents $H$. This result stems from a negative spending effect. A larger class size $H$ increases the demand for higher education. To balance the government budget, the subsidy has to fall for a given tax $t$. Moreover, the additional revenues caused by a marginal tax increase are now distributed among a larger group of recipients. Thus, the rise of the subsidy in response to a marginally higher tax turns out to be smaller, the larger the class size $H$. Since the benefits of a tax increase decline, the optimal level $t^{o}$ and the corresponding subsidy $s^{o}$ decrease.

The main conclusions are summarized in

Proposition 1 Political Preferences.

i) A parent prefers the tax $t^{\circ}$ that denotes the solution to maximisation problem (7) to all other alternatives if, and only if, $z_{j i} \leq \widetilde{z}_{j}\left(s^{o}\left(t^{o}\right), t^{o}\right)$ holds. Conversely, a 
household favours the policy $t=0$ over all other candidates if, and only if, $z_{j i}>$ $\widetilde{z}_{j}\left(s^{o}\left(t^{o}\right), t^{o}\right)$ results.

ii) The optimal tax $t^{o}$ and the corresponding subsidy $s^{o}$ strictly decrease in the size of the higher income group $H$.

Proof. See Appendix B.

Finally, note that the policy $t^{o}$ maximises the net subsidy by excluding a fraction of the young generation from higher education. Hence, enrolments definitely fall below unity for the policy outcome $\left(s^{o}, t^{o}\right)$.

\section{Education Policy and Social Stratification}

Having explored the political preferences and the relationship between taxes and subsidies, let us now turn to the final step and analyse the equilibrium and the dynamic properties of the socioeconomic system. Today's political choice determines current enrolments, which in turn fix class size and thus the society's starting position in the future. Two succeeding periods are linked via the 'inherited' number of skilled and unskilled workers. Through this connection and the impact of social stratification on political majorities, public education spending is the result of both current votes and past democratic choices.

\subsection{Election Results and the Size of Income Groups}

Since higher income and lower income supporters of a government intervention agree on their favoured policy, there is a clear-cut dichotomy of interests. The most preferred tax of a household is either $t^{o}$ or 0 , as stated in proposition 1 . In any case, one of these two proposals is favoured over all other alternatives. The electorate can thus be divided into two opposing parties, and the favourite proposal of the larger party is the Condorcet winner, the alternative that wins against any other policy at the polls in a pairwise comparison. ${ }^{11}$

Given that each stance is supported by households in both income groups, the political dispute is certainly not a 'traditional class conflict'. The main issue of the current paper is not redistribution between income groups, but redistribution between those who send their children to universities and those who do not. Despite this fact, the question of which of the two proposals gains the upper hand crucially depends on the society's social composition. As inequality (10) shows, public education spending is more popular among skilled parents than among unskilled. Since

\footnotetext{
${ }^{11}$ The clear-cut dichotomy guarantees an election winner despite the fact that not all voters have single-peaked political preferences.
} 
the children of skilled parents predominantly go to university, a larger fraction of higher income families benefits from a subsidy. This suggests that the votes in favour of the alternative $t^{o}$ increase in class size $H$. And indeed, this notion is confirmed in proposition 2 .

\section{Proposition 2 'Static' Equilibrium.}

The proposal $t^{o}$ wins the election if the size of the higher income class $H$ exceeds a threshold value $\bar{H}$. Otherwise, the proposal $t=0$ gains a majority against any other alternative.

I provide a formal proof in Appendix B and now explore the economic intuition in more detail. First, note that the number of citizens who vote for the policy $t^{o}$, and thus against the proposal $t=0$, in the decisive election is given by

$$
V\left(s^{o}\left(t^{o}\right), t^{o}\right)=\eta_{L} L+\eta_{H} H=\eta_{L}+\left[\eta_{H}-\eta_{L}\right] H
$$

where (10) is used. Since $\eta_{H}$ is greater than $\eta_{L}, V$ increases in $H$, ceteris paribus. Beside this electorate composition effect, however, there is another impact. Changes in class size also affect the optimal tax $t^{o}$, as argued in proposition 1. But this impact is only a 'second-order' effect that determines the level of the tax $t^{o}$ and of the corresponding subsidy $s^{o}$ but not whether the proposal $t^{o}$ achieves a majority. While the preferred tax of those in favour of government intervention and the corresponding subsidy indeed decrease in the number of higher income households, more skilled parents first of all strengthen the support for some public education spending. If $H$ exceeds a critical value $\bar{H}$, the proposal $t^{o}$ wins at the polls, i.e. $V \geq 0.5$ if $H \geq \bar{H}$. In this case, the majority of skilled parents supported by lower income families with talented (i.e. low costs) children decides the election in favour of the policy $t^{o}$. Otherwise, i.e. if $H<\bar{H}$ and thus $V<0.5$, a majority prefers the alternative $t=0$ and rejects any government intervention, as stated in proposition 2.

Given this 'static' election result, the precise evolution of education policy and its impact on class size can finally be analysed. Thereby, a particular focus is on the question of whether a subsidy, once introduced, is politically sustainable.

\section{2 'Educational' Take-off and Decline}

The dynamics of the system are already partly indicated in propositions 1 and 2 . As shown above, active government involvement can only gain a majority at the polls if the size of the higher income class is sufficiently large. The threshold value $\bar{H}$ might be smaller than zero or greater than one, meaning that a majority for education 
subsidies either always exists or can never be achieved. ${ }^{12}$ More interesting, however, is the case in which $\bar{H}$ lies in the open interval $(0,1)$ and will be reached over time. The resultant dynamics of the system are illustrated in figure 1 . The evolution of public education spending and social stratification is first explained step by step and afterwards summarized in proposition 3.

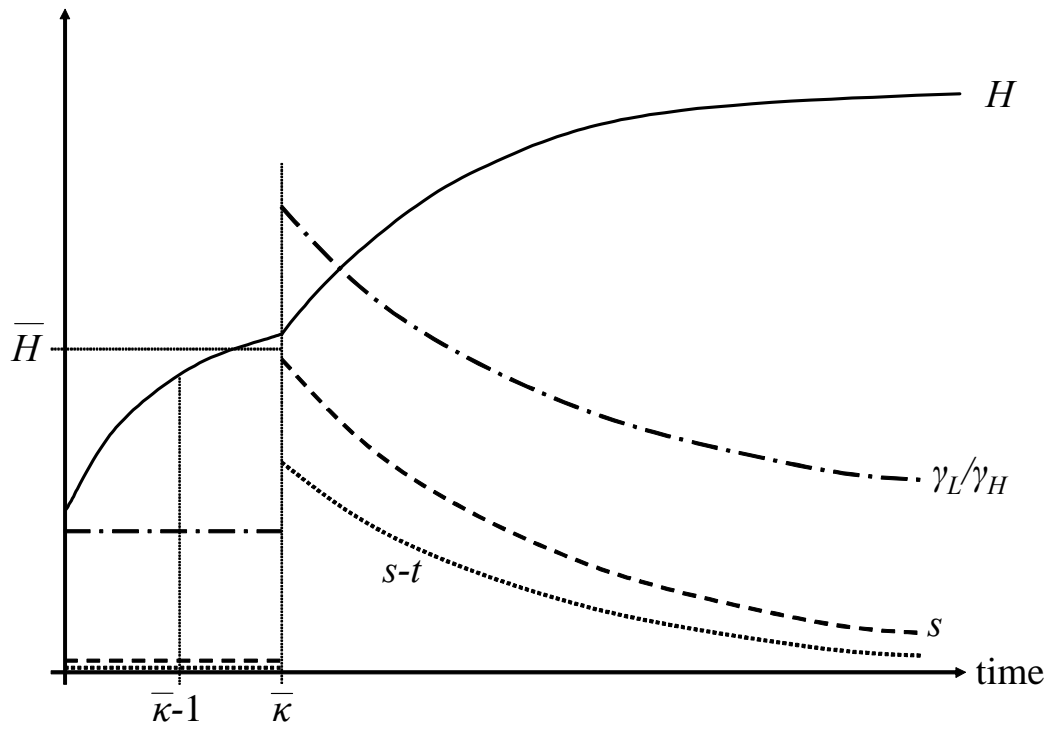

Figure 1: Evolution of Education Policy and Social Stratification

Assume that the higher income class's size in the starting period $H_{0}$ is very small and falls below $\bar{H}$ (subscripts of variables changing over time refer to the respective period). There is, thus, no majority for an active education policy at the beginning of the time horizon. But if the number of university students from lower income families outweighs the number of higher income class children who do not attend universities, the group of skilled people will grow over time. This dynamic process is described by the difference equation (6) for $s=t=0$, which relates the class size of the skilled in the next period $E_{\kappa+1}, E_{\kappa+1}=H_{\kappa}$, to its present size $H_{\kappa}$.

This development heads towards a stable steady state with no education subsidies unless the figure $H$ tops the threshold value $\bar{H}$ in any period. If wages and willingness to pay for education are rather high, or costs are sufficiently low, the class size $H$ will once be above $\bar{H}$. Suppose this is the case in period $\bar{\kappa}$, as shown in figure 1 .

\footnotetext{
${ }^{12} \mathrm{~A}$ simple sufficient condition for $\bar{H}<1$ to hold is $m w_{H}>(1 / 2)(\bar{z}+\underline{z})$. In this case, more than $50 \%$ of the higher income households send their children to universities even if the government does not intervene, and thus necessarily support the policy $t^{o}$.
} 
An 'educational' take-off then occurs, meaning that a majority of higher income and lower income households with talented children push through a tax financed education subsidy. The distributional effects of this policy are ambiguous. On the one hand, this policy is at the expense of the many unskilled parents who pay taxes but whose children only receive basic schooling. On the other hand, the public education spending indeed opens up access to universities for children from lower income families and improves the equality of opportunity. The ratio of the participation rates $\gamma_{L} / \gamma_{H}$ increases, indicating the enhanced social mobility and educational integration. The subsidy, moreover, boosts the number of students in general.

But this phase does not last forever. After a period of extension, the 'success' of the education spending causes its decline. The government intervention has fostered the change of the society's social composition. But a larger group of skilled parents increases the demand for education and thus makes publicly financed, or at least supported, universities more costly. Maintaining the same subsidy per student would require a significant tax increase. Even more, the positive impact of a marginal tax change on the subsidy is smaller, since the number of recipients has grown. In response to this negative spending effect, the supporters of government intervention now prefer lower taxes. This tax cut, combined with the demand increase, necessarily implies that the subsidies decline more than proportionally, leading to falling net subsidies $s-t$. All in all, there is still a majority for an active government role, but this majority calls for larger private contributions and pushes through a policy that leads to a drop in subsidies.

Despite the partial withdrawal of the government, the overall number of students further increases. This rise is due to the change in the society's social composition and its direct effect, namely the demand shift caused by a larger class size $H$. The induced political shift curbs the rise in enrolments because a lower net subsidy cuts the participation rate of both the lower income and the higher income classes, $\gamma_{L}$ and $\gamma_{H}$. But this indirect impact is only a secondary effect in response to the initial demand boost. Thus, the change in class size is the dominant force and drives the number of students up.

The shift in the political preferences, however, shapes the social openness of the university system and thus social stratification. Since lower income families are particularly affected by the spending cuts, the fraction of their children attending university $\gamma_{L}$ drops more than proportionally. The declining ratio $\gamma_{L} / \gamma_{H}$ indicates the deteriorating opportunities of this group. The described withdrawal of the government in the aftermath of the 'educational' take-off and the implied 'disintegration' of the society continue in the ensuing periods. Rising enrolments today further 
increase future education demand via the class-size effect. Since the subsidy system is put under even more strain, further cuts in education spending occur. While the fraction of unskilled parents drops, the remaining children from lower income families fall more and more into an education trap. The whole process finally converges towards a steady state with smaller but still positive taxes and subsidies. These dynamics of the socioeconomic system are summarised in proposition 3.

Proposition 3 Evolution of Education Policy and Social Stratification.

Assume that the system described above starts with no higher income households, i.e. $H=0$. Then, it shows the following dynamic properties:

i) The size of the skilled class and the number of students increase over time and converge towards a strictly positive value in the stable steady state. On this path, the policy $t=0$ wins the elections as long as the number of skilled parents is below the threshold value $\bar{H}$. If the number of higher income households exceeds the critical level $\bar{H}$ in period $\bar{\kappa}$, the tax $t^{o}$ will gain a majority at the polls in this and all succeeding periods, leading to the corresponding subsidy $s^{\circ}$.

ii) After introducing a strictly positive tax and subsidy in period $\bar{\kappa}$, the variables $s, t$ and the 'net' subsidy $s-t$ decrease over time and converge towards strictly positive steady state levels.

iii) The ratio of the participation rates $\gamma_{L} / \gamma_{H}$ increases in period $\bar{\kappa}$. It strictly decreases afterwards until it reaches its steady state value.

Proof. See Appendix B.

\section{Discussion}

Like all models, the present framework provides a simplified picture of the actual world. In this section, some major assumptions, their implications and some possible generalisations are briefly discussed.

First, in the current model there are no subsidies before the 'educational' take-off occurs (see figure 1). This feature certainly exaggerates the rise in public spending. Even before an expansion of the type described above takes place, some kind of government intervention is usually supported by the electorate. Many citizens who do definitely not directly gain from an education subsidy nevertheless vote for some public spending. These individuals might indirectly benefit from increased aggregate human capital because it positively affects the earnings of the uneducated (Creedy and Francois, 1990), the return on capital (Soares, 2003), and the tax base and thus the financial means for redistributive measures (Beviá and Iturbe-Ormaetxe, 2002). So the education subsidy should be positive in the pre-expansion periods. 
But this does not contradict the current arguments for an 'educational' take-off and an ensuing decline in public spending.

Second, by considering only two person families, the model suggests that a majority for public spending requires an overall participation rate that exceeds 0.5. This feature, which frequently appears in the literature on the political economics of higher education (for instance, Fernandez and Rogerson, 1995), of course overstates the number of immediate beneficiaries necessary for an expansion of the public education system to occur. It could be avoided in several ways without affecting the basic mechanisms analysed in this paper. For instance, once families with two parents and more than one child are considered, already one talented child provides sufficient incentives for the parents to support government intervention. Thus, a majority of citizens can favour an education subsidy, although only a minority of the children attends universities. Moreover, parents are well-informed about the abilities of their children, but not with absolute certainty. In the case of risk averse parents, they might vote in favour of public education spending even if the probability that their children are talented and will indeed attend a university is not particularly high. Thereby, they insure themselves against the 'costly' outcome that receiving higher education is indeed worthwhile for their children. Again, the number of parents supporting subsidies can substantially exceed the number of students.

Third, only an income-independent education subsidy is considered, although in reality we also observe regressive and progressive financial assistance. However, income-independent subsidies, mainly in the form of low, or no, tuition fees, still constitute a major component of total spending on higher education in many countries. From a political-economic perspective, progressive subsidies like means-tested grants can be seen as an instrument to broaden the support for public education spending among lower income households. They thus reduce the threshold level $\bar{H}$, but do not necessarily contradict the present conclusions.

Fourth, in the present model cuts in education spending are only reflected in a lower subsidy. Considering the expenditure patterns and the political discussions in countries like Britain and Germany, the picture that emerges is more complicated. Declining public funding per student is, at least initially, not compensated by higher private contributions, but it leads to lower education quality, reflected in rising student-staff ratios, old equipment, and so on. ${ }^{13}$ Only after this process of deterioration has continued for some time, will an intense discussion about higher private contributions begin, and moderate changes are (about being) implemented. Drastic reforms still need much more time. Therefore, the current analysis outlines

\footnotetext{
${ }^{13}$ See, for instance, Greenaway and Haynes (2003) for a brief sketch of the development of the British university system.
} 
a possible basic development rather than the precise steps.

Fifth, the present approach ignores any effects on social mobility caused by economic growth (for instance, Galor and Tsiddon, 1997, and Owen and Weil, 1998). If technological inventions and aggregate human capital positively affect general productivity and thus increase gross wages of the skilled and unskilled, they boost education demand of both income groups. This not only makes it more likely that the 'educational' take-off occurs, since wage growth decreases the threshold value $\bar{H}$. It also at least mitigates the ensuing decline in participation rates. However, if the productivity gains are skilled-biased, they mainly increase the demand for education of higher income households. This might even lower the ratio between the participation rates of the lower income and the higher income families $\gamma_{L} / \gamma_{H}$.

Sixth, considering lump-sum taxation, the current analysis focuses on the conflict between those families whose children attend universities and those who do not. If a different tax schedule is implemented, further conflicts of interests arise. In the case of a proportional or progressive tax on labour income, for example, lower income families whose children attend universities benefit twice from public education spending. They receive a subsidy financed by all households, and they contribute less in absolute terms to the tax revenues than their wealthier counterparts. Because of the additional redistributive impact, overall support for a subsidy among the lower income households is strengthened while that among higher income households is diluted. Since the latter group gains political power over time, a less regressive taxation might rather reinforce the decline in education spending. Moreover, in the case of more than two income groups, an 'ends against the middle' phenomenon similar to that in Epple and Romano (1996) might appear.

Finally, the present model implies a simple relationship between family income and private education spending. In reality, the link between social background and educational choice is certainly more complex. For instance, Sjögren (2000) argues that an individual's uncertainty about her ability to be successful in an occupation is greater in the case of occupations distant from the parents' occupation than in the case of familiar ones. Thus, risk-averse individuals tend to choose careers that are similar to those of their parents. So even in countries with modest income disparity, the family background should affect the educational and occupational choices. $^{14}$ This influence of family characteristics, however, does not mean that economic incentives are unimportant. By contrast, Sjögren (2000) shows that under certain conditions individuals from lower income families are particularly sensitive

\footnotetext{
${ }^{14}$ This notion is supported by numerous papers which stress the role of family characteristics like the human capital of parents for the children's educational attainment. See, for instance, Haveman and Wolfe (1995).
} 
to economic incentives.

\section{Conclusion}

The present paper highlights some of the underlying mechanisms that can induce an 'educational' take-off and an ensuing decline in public spending. It analyses how the political outcome interacts with the evolution of class size and the changing political preferences of the groups supporting a tax financed subsidy. As we have seen, the current call for higher private contributions might rather reflect a broad trend in public opinion than a short-lived political mood.

The line of reasoning in this paper has a simple point of departure: the demand for higher education increases in the number of educated parents because their children attend universities more than proportionally, and the families of students are those who support the respective tax financed subsidy as a means of redistributing resources to them. Given this starting point, the expansion of public spending and the ensuing cuts are driven by two opposing forces that are generated by the same source, the increasing number of skilled parents. The rise of the educated class leads to a majority for an 'educational' take-off. This expansion of public education spending further boosts the number of skilled individuals and thus future demand for higher education. This shift in demand implies that the initial subsidy becomes too expensive to be politically sustainable. Although the majority for some public spending is broadened, the preferred levels decline over time. Nevertheless, the number of students rises further, both reflecting the changing social composition and reinforcing these changes. But despite growing enrolments, the ratio between the participation rates of the lower income and the higher income families falls. Equality of opportunity deteriorates.

As argued in the previous section, the path shown describes a broad tendency rather than a precise development. The basic argument is that universities will become fenced in so that the increase in demand is at least partly depressed. An obvious strategy to achieve this goal is to require higher private contributions. There are, however, other measures that can serve this end. For instance, institutional arrangements at the school level can work in favour of social selection, thus reducing the group of potential recipients of an education subsidy. In addition to analysing the evolution of public spending on higher education, it is thus worthwhile exploring the evolution of the education system as a whole. This demands a closer look at the institutional design and particularly at the interplay between the school system and the system of higher education. These issues are left for further research. 


\section{Appendix A}

Lemma 1: Willingness to Pay for Higher Education.

A parent's maximum willingness to pay for higher education equals the fraction $m$ of the potential family consumption level $x^{\prime}$, i.e. the maximum willingness to pay for higher education will amount to $m x^{\prime}$ if the family consumes $x^{\prime}$ in the case in which the child only receives basic education. The fraction $m$ is independent of the potential consumption level and lies in the open interval $(0,1)$.

Proof. Define $m:=\left(x^{\prime}-x^{\prime \prime}\right) / x^{\prime}$. Properties (i) and (ii) guarantee the existence of a bundle $\left(x^{\prime}, x^{\prime \prime}\right)$ such that $U\left(x^{\prime}, \underline{\theta}\right)=U\left(x^{\prime \prime}, \theta\right)$ holds. Hence, for a potential family consumption level $x^{\prime}$ the maximum willingness to pay for higher education equals $x^{\prime}-x^{\prime \prime}=m x^{\prime}$. Then, property (iii) implies that a parent facing the potential family consumption level $\lambda x^{\prime}$ is ready to give up $\lambda x^{\prime}-\lambda x^{\prime \prime}=m\left(\lambda x^{\prime}\right)$. Thus, fraction $m$ does not depend on the potential consumption level. Property (i) guarantees $m>0$, and property (ii) implies $m<1$.

\section{Relationship between Subsidy and Tax for a Balanced Budget}

To make the following derivatives more accessible, the government budget is reformulated, using (4), (5) and (6):

$$
B(s, t ; H)=t-s E(s, t ; H)=t-s \frac{m\left[w_{L}+\left(w_{H}-w_{L}\right) H-t\right]+s-\underline{z}}{\bar{z}-\underline{z}},
$$

where $E(s, t ; H)$ captures the optimal education choices of the utility-maximising households. The budget constraint $B(s, t ; H)=0$ implicitly yields $s$ as a function of $t$ and $H: s=s(t ; H)$. Thus, comparative statics yields the derivative

$$
\frac{d s(t ; H)}{d t}=-\frac{\partial B(s, t ; H) / \partial t}{\partial B(s, t ; H) / \partial s}>0 .
$$

This expression leads to

$$
\frac{d^{2} s}{d t^{2}}=-\frac{\frac{\partial B}{\partial s} \frac{\partial^{2} B}{\partial t \partial s} \frac{d s}{d t}-\frac{\partial B}{\partial t}\left(\frac{\partial^{2} B}{\partial s^{2}} \frac{d s}{d t}+\frac{\partial^{2} B}{\partial t \partial s}\right)}{\left(\frac{\partial B}{\partial s}\right)^{2}},
$$

where the derivatives follow from (A1). The denominator of (A3) is positive. Denote the numerator by $\Omega$. Reformulating this term shows that $\Omega>0 \Leftrightarrow 2(\partial B / \partial s)$ $\left(\partial^{2} B / \partial t \partial s\right)-(\partial B / \partial t)\left(\partial^{2} B / \partial s^{2}\right)>0 \Leftrightarrow(\partial E / \partial s)+(\partial E / \partial t) E>0$, where the last inequality is implied by $E<1$ and

$$
\frac{\partial E}{\partial s}=\frac{1}{\bar{z}-\underline{z}}>\frac{m}{\bar{z}-\underline{z}}=-\frac{\partial E}{\partial t} .
$$


(Note that $m \in(0,1)$ according to lemma 1.) Thus, $d^{2} s / d t^{2}<0$ results.

Finally, note that the properties of the budget constraint shown above and the property $d s /\left.d t\right|_{t=0}=1 / E(0,0 ; H)>1$ imply a unique solution to $(7)$, where $s^{o}\left(t^{o}\right)>t^{o}>0$ holds.

\section{Appendix B}

\section{Proof of Proposition 1}

i) The proof follows the lines of reasoning presented in section 3. As argued there, a child either attends university or receives basic schooling. In the former case, the inequality $U\left(s^{o}\left(t^{o}\right), t^{o} ; \theta\right)=U\left(w_{j}-t^{o}+s^{o}\left(t^{o}\right)-z_{j i}, \theta\right)>U\left(w_{j}-t+s(t)-z_{j i}, \theta\right)$ $=U(s(t), t ; \theta)$ for all $t \neq t^{o}$ follows from maximisation (7). In the latter case, $U(0,0 ; \underline{\theta})=U\left(w_{j}, \underline{\theta}\right)>U\left(w_{j}-t, \underline{\theta}\right)=U_{i j}(s(t), t ; \underline{\theta})$ for all $t>0$. Consequently, if inequality (9) is fulfilled (not fulfilled), $U_{i j}\left(s^{o}\left(t^{o}\right), t^{o} ; \theta\right) \geq U_{i j}(0,0, \underline{\theta})$ $\left(U_{i j}\left(s^{o}\left(t^{o}\right), t^{o} ; \theta\right)<U_{i j}(0,0 ; \underline{\theta})\right)$ and therefore $U_{i j}\left(s^{o}\left(t^{o}\right), t^{o} ; \theta\right) \geq U_{i j}(s(t), t ; \underline{\theta})$ $\left(U_{i j}(s(t), t ; \theta)<U_{i j}(0,0 ; \underline{\theta})\right)$ for all $t$. The parent prefers the tax $t^{o}$ (the $\operatorname{tax} t=0$ ).

ii) Usual comparative statics proves the second part of proposition 1. A glance at the government budget constraint, (A1) and (A2) reveals that both $H$ and $t$ affect the first-order condition (8) directly and indirectly via $s$. Utilising these relationships, comparative statics leads to $d t / d H=-\left[d^{2} s(t ; H) /(d t d H)\right] /\left(d^{2} s(t ; H) / d t^{2}\right)$, where

$$
\frac{d^{2} s}{d t d H}=-\frac{\frac{\partial B}{\partial s} \frac{\partial^{2} B}{\partial t \partial s} \frac{\partial s}{\partial H}-\frac{\partial B}{\partial t}\left(\frac{\partial^{2} B}{\partial s^{2}} \frac{\partial s}{\partial H}+\frac{\partial^{2} B}{\partial s \partial H}\right)}{\left(\frac{\partial B}{\partial s}\right)^{2}}
$$

(cf. (A3)). The government budget constraint $B(s, t ; H)=0$ implies $\partial s(t ; H) / \partial H$ $=-[\partial B(s, t ; H) / \partial H] /[\partial B(s, t ; H) / \partial s]$. This equation, (A2), (A3), (A5) and the first order condition $d s(t ; H) / d t=1$ finally yield

$$
\frac{d t}{d H}=\frac{-\frac{\partial B}{\partial s} \frac{\partial^{2} B}{\partial s \partial H}+\frac{\partial B}{\partial H}\left(\frac{\partial^{2} B}{\partial s^{2}}+\frac{\partial^{2} B}{\partial s \partial t}\right)}{-\frac{\partial B}{\partial t}\left(\frac{\partial^{2} B}{\partial s^{2}}+2 \frac{\partial^{2} B}{\partial s \partial t}\right)}=\frac{-\frac{\partial E}{\partial H}\left[E-s\left(\frac{\partial E}{\partial s}+\frac{\partial E}{\partial t}\right)\right]}{2\left(1-s \frac{\partial E}{\partial t}\right)\left(\frac{\partial E}{\partial s}+\frac{\partial E}{\partial t}\right)},
$$

where the derivatives again follow from (A1). The denominator of (A6) is positive, since it is, of course, equal to the numerator of (A3) for $d s / d t=-[\partial B(s, t) / \partial t] /$ $[\partial B(s, t) / \partial s]=1$. Concerning the numerator, $\partial E / \partial H>0$ follows from (A1). Moreover, some simple reformulations show that $E-s(\partial E / \partial s+\partial E / \partial t)=$ $\left\{m\left[w_{L}+\left(w_{H}-w_{L}\right) H-t^{o}+s^{o}\right]-\underline{z}\right\} /(\bar{z}-\underline{z}) \in(0,1)$ because of the chain of inequalities $\bar{z}>m\left(w_{H}-t^{o}\right)+s^{o}>m\left[w_{L}+\left(w_{H}-w_{L}\right) H-t^{o}+s^{o}\right]>m w_{L}>\underline{z}$, which follows from assumption 1 and $s^{o}\left(t^{o}\right)-t^{o}>0$ (see last remark in Appendix A). Thus, the numerator is negative, and $d t / d H<0$ results. 
Finally, $d s(t ; H) / d H=\partial s(t ; H) / \partial H+(d s(t ; H) / d t)(d t / d H), d s / d t=1,(\mathrm{~A} 2)$ and (A6) lead to

$$
\frac{d s}{d H}=\frac{-\frac{\partial^{2} B}{\partial s \partial t} \frac{\partial B}{\partial H}+\frac{\partial B}{\partial t} \frac{\partial^{2} B}{\partial s \partial H}}{-\frac{\partial B}{\partial t}\left(\frac{\partial^{2} B}{\partial s^{2}}+2 \frac{\partial^{2} B}{\partial s \partial t}\right)}=\frac{-\frac{\partial E}{\partial H}}{2\left(1-s \frac{\partial E}{\partial t}\right)\left(\frac{\partial E}{\partial s}+\frac{\partial E}{\partial t}\right)}<0
$$

since the numerator is again negative.

\section{Proof of Proposition 2}

Using (A1) and (A2) to reformulate first-order condition (8) yields

$$
s^{f o c}=\frac{1}{2-m}\left\{\bar{z}-m\left[w_{L}+\left(w_{H}-w_{L}\right) H-t\right]\right\},
$$

which is referred to as $s^{f o c}$-function ( $f o c$ stands for first-order condition). Next, using (9), (10) and (11) leads to $V(s(t), t) \gtreqless 0.5 \Leftrightarrow s(t) \gtreqless s^{v}$, where

$$
s^{v}=\frac{\bar{z}+\underline{z}}{2}-m\left[w_{L}+\left(w_{H}-w_{L}\right) H\right]+t .
$$

(A9) is labelled $s^{v}$-function ( $v$ stands for 50 percent of the vote). It implies that $V\left(s^{o}\left(t^{o}\right), t^{o}\right) \gtreqless 0.5 \Leftrightarrow s^{f o c} \gtreqless s^{v}$ for $t=t^{o}$ in (A8) and (A9).

Next, let us calculate the intersection $(\widetilde{s}, \widetilde{t})$ between the two functions. This yields

$$
\tilde{t}=\frac{m}{2}\left[w_{L}+\left(w_{H}-w_{L}\right) H+\frac{\bar{z}}{2(1-m)}\right]-\frac{2-m}{4(1-m)} \underline{z},
$$

where $\partial \tilde{t} / \partial H>0$ results. Since $\partial s^{v} / \partial t=1>m /(2-m)=d s^{f o c} / d t>0$ holds, $s^{f o c} \gtreqless s^{v} \Leftrightarrow t \lesseqgtr \tilde{t}$. (Recall that $m \in(0,1)$ according to lemma 1.) Therefore, $V\left(s^{o}\left(t^{o}\right), t^{o}\right) \gtreqless 0.5 \Leftrightarrow t^{o} \lesseqgtr \tilde{t}$.

Define $\bar{H}$ as the threshold value such that $V\left(s^{o}(\bar{H}), t^{o}(\bar{H})\right)=0.5$. Consider the case where $H=\bar{H}$. In this case the point $\left(s^{o}, t^{o}\right)$ coincides with the intersection $(\widetilde{s}, \widetilde{t})$, i.e. $\left(s^{o}(\bar{H}), t^{o}(\bar{H})\right)=(\widetilde{s}(\bar{H}), \widetilde{t}(\bar{H}))$. As the optimal values $s^{o}$ and $t^{o}$ decrease in $H$ (see proposition 1, part ii), $\left.t^{o}(H) \lesseqgtr t^{o}(\bar{H})\right) \Leftrightarrow H \gtreqless \bar{H}$. By contrast, (A10) implies that $\widetilde{t}(H) \gtreqless \widetilde{t}(\bar{H}) \Leftrightarrow H \gtreqless \bar{H}$. Thus, $t^{o}(H) \lesseqgtr \widetilde{t}(H) \Leftrightarrow H \gtreqless \bar{H}$ results, which leads to $V\left(s^{o}\left(t^{o}\right), t^{o}\right) \gtreqless 0.5 \Leftrightarrow H \gtreqless \bar{H}$. Given the clear-cut dichotomy (see proposition 1, part i), this relationship completes the proof because $V\left(s^{o}\left(t^{o}\right), t^{o}\right)$ gives the fraction of citizens who choose the tax $t^{\circ}$ in the decisive vote against the proposal $t=0$.

\section{Proof of Proposition 3}

i) First, the proof shows that if $(s, t)=(0,0)$ is implemented in each period, $H$ strictly increases over time and converges towards a stable steady state $\widehat{H}(0,0)$. 
Second, I argue that if $\left(s^{o}, t^{o}\right)$ is implemented in each period, $H$ strictly increases and converges towards a stable steady state $\widehat{H}\left(s^{o}, t^{o}\right)$. Third, $\widehat{H}\left(s^{o}, t^{o}\right)>\widehat{H}(0,0)$ is shown to hold. These three parts together imply proposition $3 \mathrm{i}$ ), as argued below.

Step 1: Assume that $(s, t)=(0,0)$ is implemented in each period. In this case, the difference equation (6), which describes the evolution of the number of the skilled, reduces to $H_{\kappa}=E\left(H_{\kappa-1}\right)=\gamma_{L}(0,0)+\left[\gamma_{H}(0,0)-\gamma_{L}(0,0)\right] H_{\kappa-1}$. This in turn leads to $H_{\kappa}=\left[H_{0}-\gamma_{L} /\left(1-\gamma_{H}+\gamma_{L}\right)\right]\left(\gamma_{H}-\gamma_{L}\right)^{\kappa}+\gamma_{L} /\left(1-\gamma_{H}+\gamma_{L}\right)$. Since $\left[\gamma_{H}(0,0)-\gamma_{L}(0,0)\right] \in(0,1)$ by assumption $1, H$ strictly increases over time and converges to the stable steady state $\widehat{H}(0,0)=\gamma_{L}(0,0) /\left[1-\gamma_{H}(0,0)+\gamma_{L}(0,0)\right]$. $\widehat{H}$ is strictly positive but smaller than unity because $\gamma_{H}<1$ (again by assumption 1). Consequently, if the systems starts with $H=0$ and $\widehat{H}(0,0)<\bar{H}$ holds, $H$ never exceeds $\bar{H}$, the policy $t=0$ wins every election (see proposition 2), and $H$ increases over time and converges towards the stable steady state $\widehat{H}(0,0)$.

Step 2: Assume that $\left(s^{o}, t^{o}\right)$ is implemented in each period. In this case, (6) implies

$$
\frac{d H_{\kappa}}{d H_{\kappa-1}}=\frac{\partial E}{\partial H_{\kappa-1}}+\frac{\partial E}{\partial s} \frac{d s}{d H_{\kappa-1}}+\frac{\partial E}{\partial t} \frac{d t}{d H_{\kappa-1}}
$$

Inserting (A6) and (A7) into (A11) leads to

$$
\frac{d H_{\kappa}}{d H_{\kappa-1}}=\frac{\partial E}{\partial H}\left[1-\frac{\frac{\partial E}{\partial s}+\frac{\partial E}{\partial t}\left[E-s\left(\frac{\partial E}{\partial s}+\frac{\partial E}{\partial t}\right)\right]}{2\left(1-s \frac{\partial E}{\partial t}\right)\left(\frac{\partial E}{\partial s}+\frac{\partial E}{\partial t}\right)}\right],
$$

where the derivatives again follow from (A1). The numerator of the quotient is positive, since $\partial E / \partial s>-\partial E / \partial t>0$ (see $(\mathrm{A} 4))$ and $E-s[(\partial E / \partial s)+(\partial E / \partial t)] \in(0,1)$ (see discussion after (A6)). The denominator is positive too (cf. (A6)). Furthermore, simple reformulations show that the numerator is smaller than the denominator:

$$
\begin{gathered}
\frac{\partial E}{\partial s}+\frac{\partial E}{\partial t}\left[E-s\left(\frac{\partial E}{\partial s}+\frac{\partial E}{\partial t}\right)\right]=\frac{\partial E}{\partial s}+\frac{\partial E}{\partial t}\left[1-2 s\left(\frac{\partial E}{\partial s}+\frac{\partial E}{\partial t}\right)\right] \\
<2\left(1-s \frac{\partial E}{\partial t}\right)\left(\frac{\partial E}{\partial s}+\frac{\partial E}{\partial t}\right) \Leftrightarrow \frac{\partial E}{\partial s}>-\frac{\partial E}{\partial t}
\end{gathered}
$$

where $d s / d t=1 \Leftrightarrow-\partial B / \partial s=\partial B / \partial t \Leftrightarrow E+s \partial E / \partial s=1-s \partial E / \partial t$ and (A4) are utilised. Thus, the whole term in the brackets is positive and smaller than one. In addition, $\partial E / \partial H=\gamma_{H}-\gamma_{L} \in(0,1)$ holds. Therefore, $d H_{\kappa} / d H_{\kappa-1} \in$ $(0,1)$ results. That means that $H$ converges to a stable steady state $\widehat{H}\left(s^{o}, t^{o}\right)=$ $\gamma_{L}\left(s^{o}, t^{o}\right) /\left[1-\gamma_{H}\left(s^{o}, t^{o}\right)+\gamma_{L}\left(s^{o}, t^{o}\right)\right]$. (Note that $\left(s^{o}, t^{o}\right)$ remains constant over time if, and only if, $H$ does not change.) Moreover, $\widehat{H}\left(s^{o}, t^{o}\right) \in(0,1)$ follows from $\gamma_{H}<1$ (see assumption 1).

Step 3: The relationships $1-\gamma_{H}(0,0)+\gamma_{L}(0,0)=1-\left[m\left(w_{H}-w_{L}\right)\right] /(\bar{z}-\underline{z})=$ $1-\gamma_{H}\left(s^{o}, t^{o}\right)+\gamma_{L}\left(s^{o}, t^{o}\right)(\mathrm{cf} . \quad(4)$ and $(5))$ and $\gamma_{L}(0,0)=\left(m w_{L}-\underline{z}\right) /(\bar{z}-\underline{z})<$ $\left[m\left(w_{L}-t^{o}\right)+s^{o}-\underline{z}\right] /(\bar{z}-\underline{z})=\gamma_{L}\left(s^{o}, t^{o}\right)$, which follows from $s^{o}>t^{o}$ (see last remark in Appendix A), lead to $\widehat{H}(0,0)<\widehat{H}\left(s^{o}, t^{o}\right)$. If the system starts with 
$H=0$ and $\widehat{H}(0,0)>\bar{H}$ holds, $H$ exceeds $\bar{H}$ in some period $\bar{\kappa}$. From step 1 , we know that $H$ increases until period $\bar{\kappa}$. Then, the policy $t^{o}$ wins the election and the dynamics is described by (A12). Since $H<\widehat{H}(0,0)$ still holds in period $\bar{\kappa}, H$ is still below $\widehat{H}\left(s^{o}, t^{o}\right)$. Therefore, $H$ further increases in the succeeding periods (see step 2 ) and the proposal $t^{o}$ wins each election from period $\bar{\kappa}$ on (see proposition 2 ) until $\widehat{H}\left(s^{o}, t^{o}\right)$ is reached in the stable steady state.

ii) As shown above, $H$ increases further in the periods following $\bar{\kappa}$ and converges towards its steady state level. Thus, $d s / d H<0$ and $d t / d H<0$ (see proposition 1 , part ii) imply that the variables $s^{o}$ and $t^{o}$ decrease over time, converging to their levels in the stable steady state. Showing the relation $\partial\left(s^{o}-t^{o}\right) / \partial H<0$ is sufficient to prove that $(s-t)$ also declines from period $\bar{\kappa}$ on (towards the steady state level). Using (A6) and (A7) yields

$$
\frac{\partial(s-t)}{\partial H}=\frac{-\frac{\partial E}{\partial H}\left\{1-\left[E-s\left(\frac{\partial E}{\partial s}+\frac{\partial E}{\partial t}\right)\right]\right\}}{2\left(1-s \frac{\partial E}{\partial t}\right)\left(\frac{\partial E}{\partial s}+\frac{\partial E}{\partial t}\right)} .
$$

The denominator is positive (cf. (A6)). By contrast, the numerator is negative because $\partial E / \partial H>0$ follows from $(\mathrm{A} 1)$ and $E-s[(\partial E / \partial s)+(\partial E / \partial t)] \in(0,1)$ holds (see discussion after $(\mathrm{A} 6))$. All in all, $\partial(s-t) / \partial H<0$ results. Finally, the last remark in Appendix A implies that $s^{o}, t^{o}$ and $s^{o}-t^{o}$ are strictly positive.

iii) First, $\gamma_{L} / \gamma_{H}=\left[m\left(w_{L}-t\right)+s-\underline{z}\right] /\left[m\left(w_{H}-t\right)+s-\underline{z}\right]$ is positively correlated with the term $[s-m t]$, i.e.

$$
\frac{\partial\left(\gamma_{L} / \gamma_{H}\right)}{\partial[s-m t]}=\frac{m\left(w_{H}-w_{L}\right)}{\left[m\left(w_{H}-t\right)+s-\underline{z}\right]^{2}}>0
$$

Second, the inequalities $\partial s / \partial H<0, \partial t / \partial H<0$ and $\partial(s-t) / \partial H<0$ (see (A6), (A7) and (A14)) imply $(\partial s / \partial H)-m(\partial t / \partial H)<(\partial s / \partial H)-(\partial t / \partial H)<0$, which in turn leads to $\partial[s-m t] / \partial H<\partial(s-t) / \partial H<0$. Consequently, the term $[s-m t]$ moves in the same direction as $(s-t)$ does over time. This relationship in connection with (A15) and ii) completes the proof.

\section{References}

Andersson, F., and Konrad, K.A. (2003), Human Capital Investment and Globalisation in Extortionary States, Journal of Public Economics 87, 1539-1555.

Bénabou, R. (2002), Tax and Education Policy in a Heterogenous-Agent Economy: What Levels of Redistribution maximize Growth and Efficiency, Econometrica 70, 481-517. 
Beviá, C., and Iturbe-Ormaetxe, I. (2002), Redistribution and Subsidies for Higher Education, Scandinavian Journal of Economics 104, 321-340.

BMBF (German Federal Ministry for Education and Research, ed.) (1998), Das soziale Bild der Studentenschaft in der Bundesrepublik Deutschland. 15. Sozialerhebung des deutschen Studentenwerks, Bonn.

Cardak, B.A. (2004), Ability, Education, and Income Inequality, Journal of Public Economic Theory 6, 239-276.

Creedy, J., and Francois, P. (1990), Financing Higher Education and Majority Voting, Journal of Public Economics 43, 181-200.

De Fraja, G. (2001), Education Policies: Equity, Efficiency and Voting Equilibrium, Economic Journal 111, C104-C119.

Economist, The (2003), The Point of Tony: Tony Blair is risking his Job for Top-up Fees. Why do they matter so much to him?, 6 December 2003, 36.

Epple, D., and Romano, R.E. (1996), Ends against the Middle: Determining Public Service Provision when there are Private Alternatives, Journal of Public Economics 62, 297-325.

Fernandez, R., and Rogerson, R. (1995), On the Political Economy of Education Subsidies, Review of Economic Studies 62, 249-262.

Galor, O. and Tsiddon, D. (1997), Technological Progress, Mobility, and Economic Growth, American Economic Review 87, 363-382.

Glomm, G., and Ravikumar, B. (1992), Public versus Private Investment in Human Capital: Endogenous Growth and Income Inequality, Journal of Political Economy 100, 818-834.

Glomm, G., and Ravikumar, B. (2003), Public Education and Income Inequality, European Journal of Political Economy 19, 289-300.

Gradstein, M., and Justman, M. (1997), Democratic Choice of an Education System: Implications for Growth and Income Distribution, Journal of Economic Growth 2, 169-183.

Greenaway, D., and Haynes, M. (2003), Funding Higher Education in the UK: The Role of Fees and Loans, Economic Journal 113, F150-F166.

Haupt, A., and Janeba, E. (2004), Education, Redistribution, and the Threat of Brain Drain, NBER Working Paper Series 10618, Cambridge, MA. 
Haveman, R., and Wolfe, B. (1995), The Determinants of Children's Attainments: A Review of Methods and Findings, Journal of Economic Literature XXXIII, 1829-1878.

Iyigun, M. F. (1999), Public Education and Intergenerational Economic Mobility, International Economic Review 40, 697-710.

Loury, G.C. (1981), Intergenerational Transfers and the Distribution of Earnings, Econometrica 49, 843-867.

Owen, A.L., and Weil, D.N. (1998), Intergenerational Earning Mobility, Inequality and Growth, Journal of Monetary Economics 41, 71-104.

Perotti, R. (1993), Political Equilibrium, Income Distribution, and Growth, Review of Economic Studies 60, 755-776.

Poutvaara, P. (2001), Alternative Tax Constitutions and Risky Education in a Federation, Regional Science and Urban Economics 31, 355-377.

Robertson, D., and Hillman, J. (1997), Widening Participation in Higher Education for Students from Lower Socio-Economic Groups and Students with Disabilities, Report 6 for The National Committee of Inquiry into Higher Education, London.

Saint-Paul, G., and Verdier, T. (1993), Education, Democracy and Growth, Journal of Development Economics 42, 399-407.

Sjögren, A. (2000), Occupational Choice and Incentives: The Role of Family Background, Working Paper 539, Research Institute of Industrial Economics, Stockholm.

Soares, J. (2003), Self-Interest and Public Funding of Education, Journal of Public Economics 87, 703-727.

Wildasin, D.E. (2000), Labor-Market Integration, Investment in Risky Human Capital, and Fiscal Competition, American Economic Review 90, 73-95. 


\section{CESifo Working Paper Series}

(for full list see www.cesifo-group.de)

1565 Joerg Breitung and M. Hashem Pesaran, Unit Roots and Cointegration in Panels, October 2005

1566 Steven Brakman, Harry Garretsen and Marc Schramm, Putting New Economic Geography to the Test: Free-ness of Trade and Agglomeration in the EU Regions, October 2005

1567 Robert Haveman, Karen Holden, Barbara Wolfe and Andrei Romanov, Assessing the Maintenance of Savings Sufficiency Over the First Decade of Retirement, October 2005

1568 Hans Fehr and Christian Habermann, Risk Sharing and Efficiency Implications of Progressive Pension Arrangements, October 2005

1569 Jovan Žamac, Pension Design when Fertility Fluctuates: The Role of Capital Mobility and Education Financing, October 2005

1570 Piotr Wdowinski and Aneta Zglinska-Pietrzak, The Warsaw Stock Exchange Index WIG: Modelling and Forecasting, October 2005

1571 J. Ignacio Conde-Ruiz, Vincenzo Galasso and Paola Profeta, Early Retirement and Social Security: A Long Term Perspective, October 2005

1572 Johannes Binswanger, Risk Management of Pension Systems from the Perspective of Loss Aversion, October 2005

1573 Geir B. Asheim, Wolfgang Buchholz, John M. Hartwick, Tapan Mitra and Cees Withagen, Constant Savings Rates and Quasi-Arithmetic Population Growth under Exhaustible Resource Constraints, October 2005

1574 Christian Hagist, Norbert Klusen, Andreas Plate and Bernd Raffelhueschen, Social Health Insurance - the Major Driver of Unsustainable Fiscal Policy?, October 2005

1575 Roland Hodler and Kurt Schmidheiny, How Fiscal Decentralization Flattens Progressive Taxes, October 2005

1576 George W. Evans, Seppo Honkapohja and Noah Williams, Generalized Stochastic Gradient Learning, October 2005

1577 Torben M. Andersen, Social Security and Longevity, October 2005

1578 Kai A. Konrad and Stergios Skaperdas, The Market for Protection and the Origin of the State, October 2005

1579 Jan K. Brueckner and Stuart S. Rosenthal, Gentrification and Neighborhood Housing Cycles: Will America's Future Downtowns be Rich?, October 2005 
1580 Elke J. Jahn and Wolfgang Ochel, Contracting Out Temporary Help Services in Germany, November 2005

1581 Astri Muren and Sten Nyberg, Young Liberals and Old Conservatives - Inequality, Mobility and Redistribution, November 2005

1582 Volker Nitsch, State Visits and International Trade, November 2005

1583 Alessandra Casella, Thomas Palfrey and Raymond Riezman, Minorities and Storable Votes, November 2005

1584 Sascha O. Becker, Introducing Time-to-Educate in a Job Search Model, November 2005

1585 Christos Kotsogiannis and Robert Schwager, On the Incentives to Experiment in Federations, November 2005

1586 Søren Bo Nielsen, Pascalis Raimondos-Møller and Guttorm Schjelderup, Centralized vs. De-centralized Multinationals and Taxes, November 2005

1587 Jan-Egbert Sturm and Barry Williams, What Determines Differences in Foreign Bank Efficiency? Australian Evidence, November 2005

1588 Steven Brakman and Charles van Marrewijk, Transfers, Non-Traded Goods, and Unemployment: An Analysis of the Keynes - Ohlin Debate, November 2005

1589 Kazuo Ogawa, Elmer Sterken and Ichiro Tokutsu, Bank Control and the Number of Bank Relations of Japanese Firms, November 2005

1590 Bruno Parigi and Loriana Pelizzon, Diversification and Ownership Concentration, November 2005

1591 Claude Crampes, Carole Haritchabalet and Bruno Jullien, Advertising, Competition and Entry in Media Industries, November 2005

1592 Johannes Becker and Clemens Fuest, Optimal Tax Policy when Firms are Internationally Mobile, November 2005

1593 Jim Malley, Apostolis Philippopoulos and Ulrich Woitek, Electoral Uncertainty, Fiscal Policy and Macroeconomic Fluctuations, November 2005

1594 Assar Lindbeck, Sustainable Social Spending, November 2005

1595 Hartmut Egger and Udo Kreickemeier, International Fragmentation: Boon or Bane for Domestic Employment?, November 2005

1596 Martin Werding, Survivor Benefits and the Gender Tax Gap in Public Pension Schemes: Observations from Germany, November 2005

1597 Petra Geraats, Transparency of Monetary Policy: Theory and Practice, November 2005 
1598 Christian Dustman and Francesca Fabbri, Gender and Ethnicity - Married Immigrants in Britain, November 2005

1599 M. Hashem Pesaran and Martin Weale, Survey Expectations, November 2005

1600 Ansgar Belke, Frank Baumgaertner, Friedrich Schneider and Ralph Setzer, The Different Extent of Privatisation Proceeds in EU Countries: A Preliminary Explanation Using a Public Choice Approach, November 2005

1601 Jan K. Brueckner, Fiscal Federalism and Economic Growth, November 2005

1602 Steven Brakman, Harry Garretsen and Charles van Marrewijk, Cross-Border Mergers and Acquisitions: On Revealed Comparative Advantage and Merger Waves, November 2005

1603 Erkki Koskela and Rune Stenbacka, Product Market Competition, Profit Sharing and Equilibrium Unemployment, November 2005

1604 Lutz Hendricks, How Important is Discount Rate Heterogeneity for Wealth Inequality?, November 2005

1605 Kathleen M. Day and Stanley L. Winer, Policy-induced Internal Migration: An Empirical Investigation of the Canadian Case, November 2005

1606 Paul De Grauwe and Cláudia Costa Storti, Is Monetary Policy in the Eurozone less Effective than in the US?, November 2005

1607 Per Engström and Bertil Holmlund, Worker Absenteeism in Search Equilibrium, November 2005

1608 Daniele Checchi and Cecilia García-Peñalosa, Labour Market Institutions and the Personal Distribution of Income in the OECD, November 2005

1609 Kai A. Konrad and Wolfgang Leininger, The Generalized Stackelberg Equilibrium of the All-Pay Auction with Complete Information, November 2005

1610 Monika Buetler and Federica Teppa, Should you Take a Lump-Sum or Annuitize? Results from Swiss Pension Funds, November 2005

1611 Alexander W. Cappelen, Astri D. Hole, Erik Ø. Sørensen and Bertil Tungodden, The Pluralism of Fairness Ideals: An Experimental Approach, December 2005

1612 Jack Mintz and Alfons J. Weichenrieder, Taxation and the Financial Structure of German Outbound FDI, December 2005

1613 Rosanne Altshuler and Harry Grubert, The Three Parties in the Race to the Bottom: Host Governments, Home Governments and Multinational Companies, December 2005

1614 Chi-Yung (Eric) Ng and John Whalley, Visas and Work Permits: Possible Global Negotiating Initiatives, December 2005 
1615 Jon H. Fiva, New Evidence on Fiscal Decentralization and the Size of Government, December 2005

1616 Andzelika Lorentowicz, Dalia Marin and Alexander Raubold, Is Human Capital Losing from Outsourcing? Evidence for Austria and Poland, December 2005

1617 Aleksander Berentsen, Gabriele Camera and Christopher Waller, Money, Credit and Banking, December 2005

1618 Egil Matsen, Tommy Sveen and Ragnar Torvik, Savers, Spenders and Fiscal Policy in a Small Open Economy, December 2005

1619 Laszlo Goerke and Markus Pannenberg, Severance Pay and the Shadow of the Law: Evidence for West Germany, December 2005

1620 Michael Hoel, Concerns for Equity and the Optimal Co-Payments for Publicly Provided Health Care, December 2005

1621 Edward Castronova, On the Research Value of Large Games: Natural Experiments in Norrath and Camelot, December 2005

1622 Annette Alstadsæter, Ann-Sofie Kolm and Birthe Larsen, Tax Effects, Search Unemployment, and the Choice of Educational Type, December 2005

1623 Vesa Kanniainen, Seppo Kari and Jouko Ylä-Liedenpohja, Nordic Dual Income Taxation of Entrepreneurs, December 2005

1624 Lars-Erik Borge and Linn Renée Naper, Efficiency Potential and Efficiency Variation in Norwegian Lower Secondary Schools, December 2005

1625 Sam Bucovetsky and Andreas Haufler, Tax Competition when Firms Choose their Organizational Form: Should Tax Loopholes for Multinationals be Closed?, December 2005

1626 Silke Uebelmesser, To go or not to go: Emigration from Germany, December 2005

1627 Geir Haakon Bjertnæs, Income Taxation, Tuition Subsidies, and Choice of Occupation: Implications for Production Efficiency, December 2005

1628 Justina A. V. Fischer, Do Institutions of Direct Democracy Tame the Leviathan? Swiss Evidence on the Structure of Expenditure for Public Education, December 2005

1629 Torberg Falch and Bjarne Strøm, Wage Bargaining and Political Strength in the Public Sector, December 2005

1630 Hartmut Egger, Peter Egger, Josef Falkinger and Volker Grossmann, International Capital Market Integration, Educational Choice and Economic Growth, December 2005

1631 Alexander Haupt, The Evolution of Public Spending on Higher Education in a Democracy, December 2005 